\title{
Experimental investigation of forming limit curves and deformation features in warm forming of an aluminium alloy
}

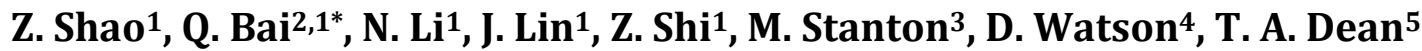 \\ ${ }^{1}$ Department of Mechanical Engineering, Imperial College London, London SW7 2AZ, UK \\ ${ }^{2}$ Key Laboratory for Precision and Non-traditional Machining Technology of Ministry of Education, Dalian \\ University of Technology, Dalian 116024, China \\ 3 Jaguar Land Rover, Banbury Road, Gaydon, Warwickshire CV35 ORR, UK \\ ${ }^{4}$ Jaguar Cars Limited, Abbey Road, Gaydon, Whitley, Coventry CV3 4LF, UK \\ ${ }^{5}$ School of Mechanical Engineering, University of Birmingham, Birmingham B15 2TT, UK
}

\begin{abstract}
:
The determination of forming limit curves (FLCs) and deformation features of AA5754 aluminium alloy are studied in this paper. The robust and repeatable experiments were conducted at a warm forming temperature range of $200-300^{\circ} \mathrm{C}$ and at a forming speed range of $20-300 \mathrm{~mm} / \mathrm{s}$. The FLCs of AA5754 at elevated temperatures with different high forming speeds have been obtained. The effects of forming speed and temperature on limiting dome height $(\mathrm{LDH})$, thickness variation and fracture location are discussed. The results show that higher temperatures and lower forming speeds are beneficial to increase forming limits of AA5754; however, lower temperatures and higher forming speeds contribute to enhancing the thickness uniformity of formed specimens. The decreasing forming speed and increasing temperature result in the locations of fracture to move away from the apexes of formed specimens. It is found that the analysis of deformation features can provide a guidance to understand warm forming process of aluminium alloys.
\end{abstract}

Keywords: Aluminium alloy; Warm forming; Experimental investigation; Forming limit curve; Forming parameter; Deformation feature

\footnotetext{
*Corresponding author. Tel.: +44 (0) 2075949078

Email address: q.bai08@imperial.ac.uk
} 


\section{Introduction}

AA5754, a strain hardening aluminium alloy, is increasingly used to reduce the weight of components and structures in the automotive industry. This is due to its characteristic properties such as moderately high strength and stiffness to weight ratio, good weldability and formability and a high level of corrosion resistance ${ }^{1}$. As one of the 5000 series aluminium alloys, AA5754 tends to suffer from stretcher lines, which gives an uneven surface after deformation; therefore it is generally used for producing inner panels of vehicles $^{2}$.

Due to the formability of AA5754 being limited at room temperature, several new metal forming techniques have been studied to improve it, such as hydroforming, hot forming and warm forming. Hydroforming of sheet metals can improve the formability of an alloy and the quality of product. It has a clear advantage in producing complex-shaped sheet metal parts ${ }^{3}$ but there are limited applications of this technology in mass production because of some disadvantages such as poor cycle times and high costs of equipment. Hot forming of sheet metals is conducted at a temperature higher than the recrystallization temperature. It is less used for forming complex-shaped parts of aluminium alloys compared to those of high strength steels. This is because microstructure evolution during high temperature deformation is unstable on account of recovery, recrystallization and grain growth for aluminium ${ }^{4-5}$.

Warm forming has the advantage of improving the formability of metal sheets by use of an elevated forming temperature which increases alloy ductility and thus reduces localized necking and fracture by changing the material properties, compared to the forming at room temperature $^{6}$. During past decades, there have been significant investigations on warm forming of AA5754 in attempts to enhance feasible shape complexity. Typical warm forming 
temperatures of aluminium alloys are in a range of $150-350^{\circ} \mathrm{C}$, which are below the recrystallization temperature of aluminium alloys ${ }^{7}$. Various investigations on AA5754 were conducted to obtain the material properties, such as the anisotropic behaviour of AA5754 over elevated temperatures ${ }^{8}$, deformation mechanisms in this material at high temperatures and strain rates $^{9}$ and sheet thermo-hydroforming of AA5754 at different temperatures and pressures ${ }^{9}$.

A forming limit curve (FLC) is a useful criterion for characterizing the formability of sheet metals $^{10-12}$. The FLC represents the boundary between uniform deformation and the onset of plastic instability or diffuse necking which leads to failure ${ }^{13}$. It is necessary to obtain the FLCs of sheet metals and analyse experimental data of forming tests to understand the deformation features at different forming conditions, and thus to increase the extent of formability. Many theoretical, experimental and numerical methods have been employed to determine the FLCs of a certain materials ${ }^{14}$. Two common methods include Marciniak test and Nakajima test: the former is a conventional method to determine the forming limit of a material avoiding friction effects, while the latter is the most commonly used method to measure the forming limit for comparison purposes. A hemispherical punch is used in Nakajima formability test to deform specimens of specific shape, corresponding to different test strain paths. In the ISO standard (ISO 12004-2:2008) ${ }^{15}$, strain is obtained by measuring grids pre-applied on the surface of the specimen, and then FLCs are determined. With regard to warm/hot formability tests, formability tests of type 5083 aluminium-magnesium alloy were performed at the temperature range of $20^{\circ} \mathrm{C}$ to $300^{\circ} \mathrm{C}$ and at forming speeds up to $3.33 \mathrm{~mm} / \mathrm{s}$ by using a warm punch to heat the metal sheets ${ }^{16}$. Similar forming tests for obtaining the FLCs of aluminium alloys including AA5754 have been performed with different die-punch temperatures from $20^{\circ} \mathrm{C}$ to over $300^{\circ} \mathrm{C}^{6}$. The effects of strain rate and 
temperature on the FLCs of AZ31 magnesium alloy were also investigated ${ }^{17}$. It was found that extrinsic factors such as temperature, strain rate, the quality of lubrication, etc. have dominant effects on forming limit tests; as a result, the effect of these process parameters on formability must be investigated to gain a thorough understanding of process mechanics.

Although a number of studies have been carried out on FLCs for aluminium alloy AA5754 at high temperatures, it is difficult to provide an ideal isothermal environment at a high test speed for formability test by using a punch with an embedding heating system. Different heating methods will lead to inconsistent and erroneous results which will be different for alloys. In addition little research was conducted to analyse deformation features such as thickness variation of formed parts and the position of necking or fracture, despite the fact that the thickness uniformity of formed specimens is a contributing factor to quality of a formed part and even the extent of the formability. Furthermore, in order to propose a set of constitutive equations to predict material failure during deformation, it is necessary to conduct formability tests of AA5754 at elevated temperatures and different strain rates to verify the accuracy of prediction.

In this paper, FLCs of AA5754 under warm forming conditions are determined by improved Nakajima tests in an isothermal environment. Tooling and test-pieces were heated and soaked at designated temperatures in a monitorable electronic furnace in order to obtain highly uniform temperature distribution. The punch speed was up to $300 \mathrm{~mm} / \mathrm{s}$ at elevated temperature, which is significant for industry applications. Deformation features of formed specimens, relating to the quality and formability of AA5754 specimens, are discussed systematically based on formability test results to evaluate quality of formed parts. Viscoplastic theory was used to analyse the occurrence of localized necking under various 
forming conditions. In order to obtain a more uniform thickness distribution and a larger extent of the formability, the effects of forming parameters, i.e. forming speed and temperature, are studied in this paper. Obtained experimental results of FLCs of AA5754 are necessary and useful for calibrating material models in future FE simulation.

\section{Experimental Programme}

\section{Materials and specimen design}

Following the internationally recognised standard for determination of forming limit curves, the geometry of the specimens produced from commercial alloy AA5754was a waisted circular shape with a central parallel section, except for the equi-biaxial specimen which was circular. The geometric shape of the specimen corresponds to a particular strain state in the tests and the rolling direction is shown in Figure1 (a). To obtain a wide range of FLCs, different ratios of parallel section length $(\mathrm{L}=30 \mathrm{~mm})$ to parallel section width $(\mathrm{W})$ were used to obtain different strain paths (different ratios of minor strain to major strain) from uniaxial tension ( $\mathrm{L} / \mathrm{W}=0.8$, Point 1) to equi-biaxial tension ( $\mathrm{L} / \mathrm{W}=5.3$, Point 6 ) as shown in the schematic FLC (Figure 1(b)). Points 1, 3 and 6, which indicate strain ratios for uniaxial tension, plane strain and equi-biaxial tension, are necessary for determining shape of an FLC, and Point 2, 4 and 5 are supplementary for the curve. The original thickness of the aluminium alloy sheet was $1.5 \mathrm{~mm}$, and the outer diameter of the specimens was $160 \mathrm{~mm}$. The primary chemical compositions contain $\mathrm{Al}-96.07 \%, \mathrm{Mg}-3.2 \%, \mathrm{Mn}-0.45 \%, \mathrm{Fe}-0.16 \%, \mathrm{Si}-0.08 \%$. Uniaxial tensile tests of AA5754 were conducted at different elevated temperatures and strain rates, with the tensile axis parallel to the rolling direction. The derived mechanical properties have been presented in a paper $^{18}$. 


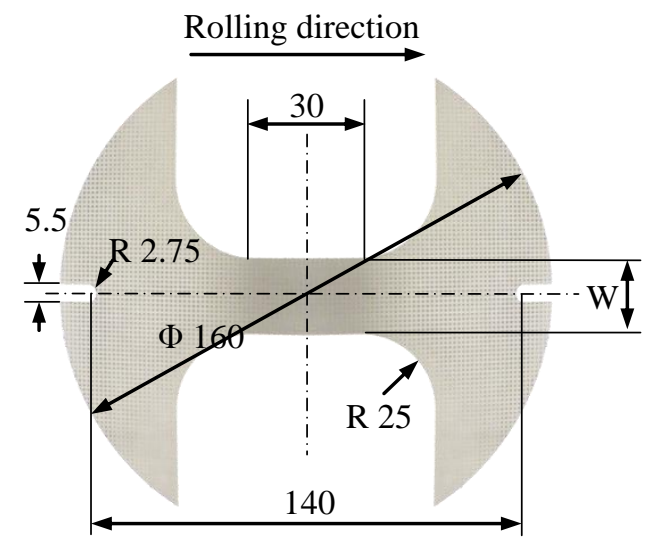

\begin{tabular}{ccc}
\hline $\begin{array}{c}\text { Geometry } \\
\text { No. }\end{array}$ & W/mm & Test type \\
\hline 1 & 24 & Uniaxial tension \\
2 & 64 & Close to plane strain \\
3 & 80 & Plane strain \\
4 & 88 & Close to plane strain \\
5 & 92 & Between No.4 and 6 \\
6 & 160 & Equi-biaxial tension \\
\hline
\end{tabular}

(a) Blank geometry numbers and corresponding dimensions (mm)

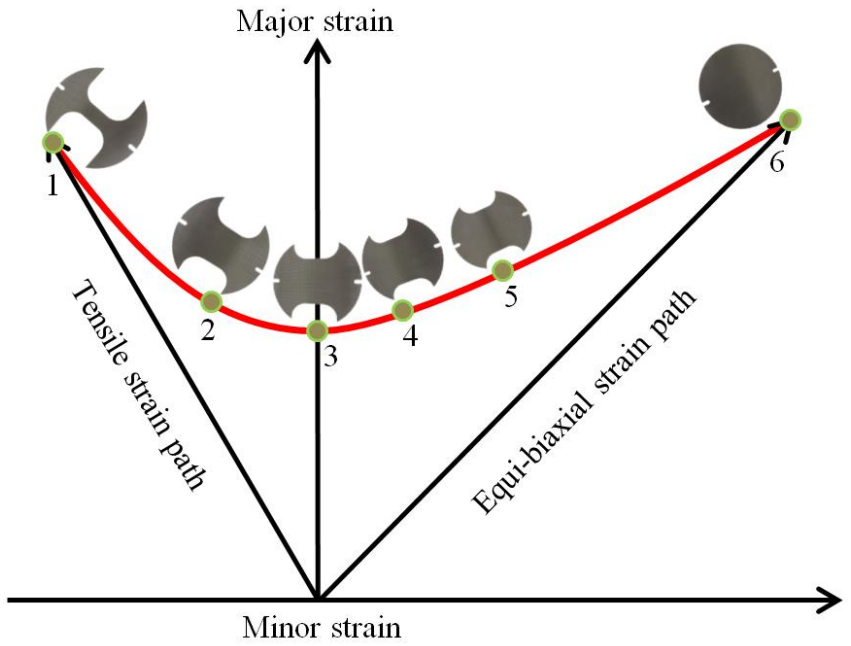

(b) Schematic drawing of the test points in the FLC

Figure 1. Geometry, dimensions and corresponding strain states of specimens in the FLC

\section{Tool design}

Warm forming tests were carried out on a 25 tonne high-speed hydraulic press (Figure 2(a)) with built-in furnace (Figure 2(b)) for the purpose of testing at elevated temperatures in an isothermal environment. A hemispherical punch with a diameter of $80 \mathrm{~mm}$ was mounted in the furnace and connected to a load cell via a stainless steel rod. A blank holder with a draw bead of $104 \mathrm{~mm}$ diameter was designed to prevent the sheet from drawing in during the tests, so that the deformation occurred solely by stretching ${ }^{19}$. An oscilloscope was connected to the 
control unit of the press to record load and displacement which were used to calculate the forming speed.

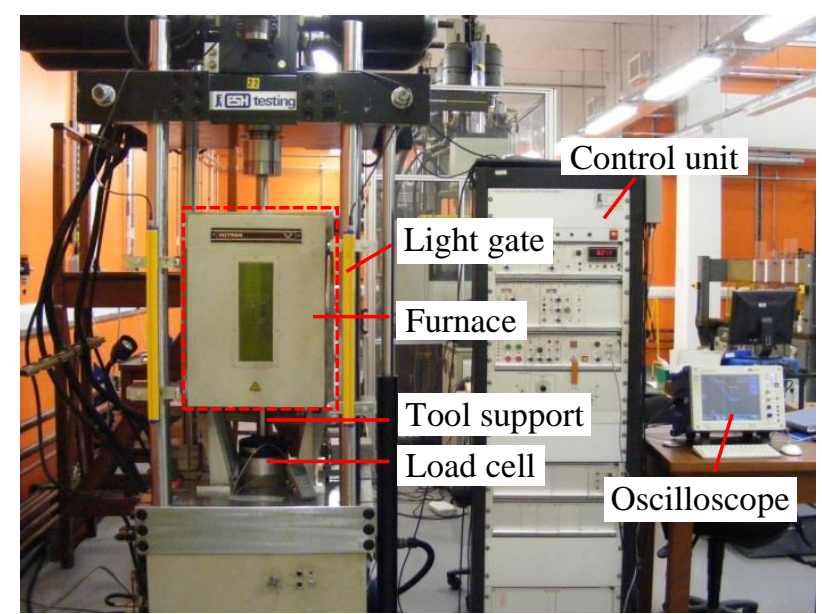

(a) The setup of test rig

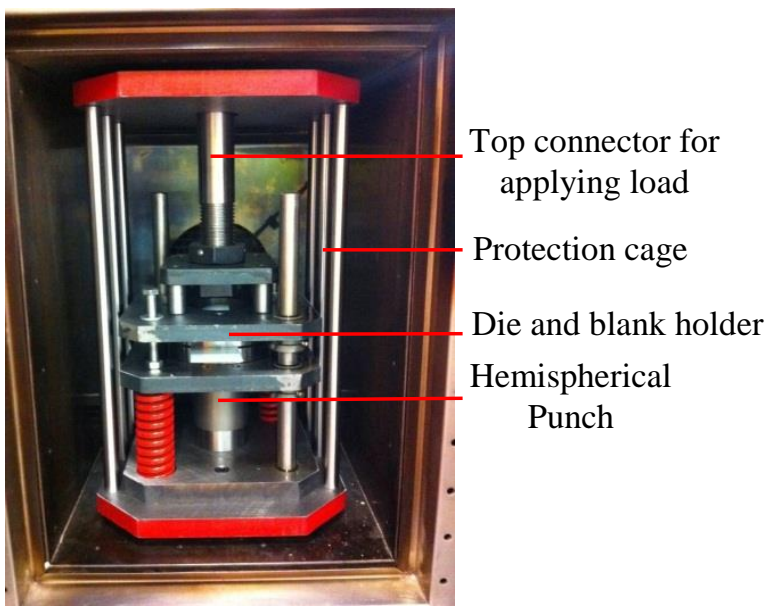

(b) The tool within furnace

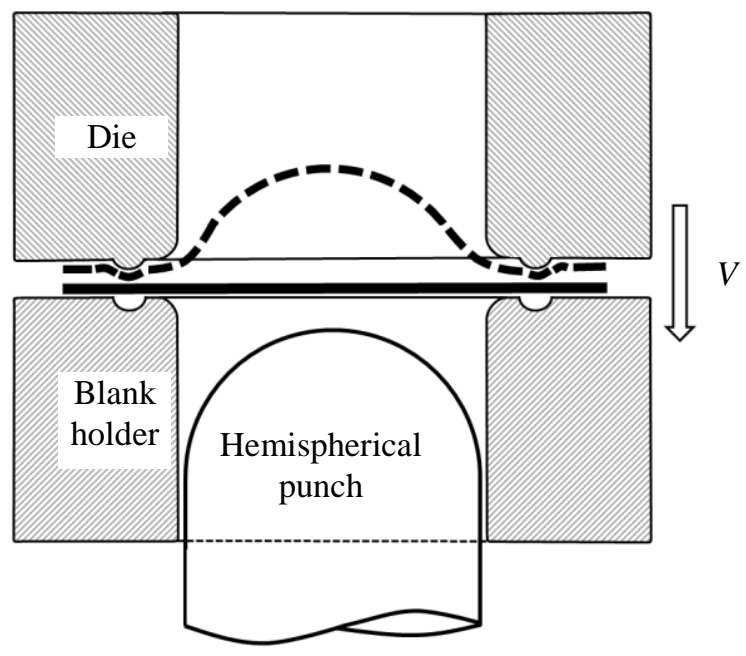

(b) Schematic of dome forming tool

Figure 2. Formability test rig equipped on a 25 tonne ESH high-speed press with an Instron furnace and schematic diagram of the forming test.

\section{Experimental procedure and data processing}

A GOM ARGUS system was used to analyse strain distribution in a formed specimen. A uniform grid pattern of $0.75 \mathrm{~mm}$ diameter circular dots with a $1.5 \mathrm{~mm}$ centre-to-centre spacing was etched to the surface of metal sheets electrochemically by the EU500 electrolytic marking system prior to forming. 
Two sets of tests were carried out at a temperature of $200-300^{\circ} \mathrm{Cwitha}$ forming speed of $75 \mathrm{~mm} / \mathrm{s}$, and at a forming speed of $20-300 \mathrm{~mm} / \mathrm{s}$ with a temperature of $250^{\circ} \mathrm{C}$, in order to investigate the effect of temperature and forming speed. The specimen was placed on the lower blank holder and two cut notches on the specimen were aligned with the two pins on the blank holder. The lubricant of Hi-Temp MSL Grease (Omega 35), which can resist temperature up to $700^{\circ} \mathrm{C}$, were pre-applied to the central area of the specimens which became in contact with the punch during the forming process. When the temperature in the furnace reached the required value, the AA5754 sheet was formed by the punch at a specific speed (Figure 2(c)). The final stroke position was set to an estimated failure position after trial runs. The performed forming test was repeated at least three times at one condition in order to assure the reliability of the test. Figure 3 shows the formed specimens at a speed of $75 \mathrm{~mm} / \mathrm{s}$ and at different temperatures. Since the intermediate stretching strain states for Point 2,4 and 5 in Figure 1 affect little the trend of FLCs, they were not formed under all combinations of forming conditions.

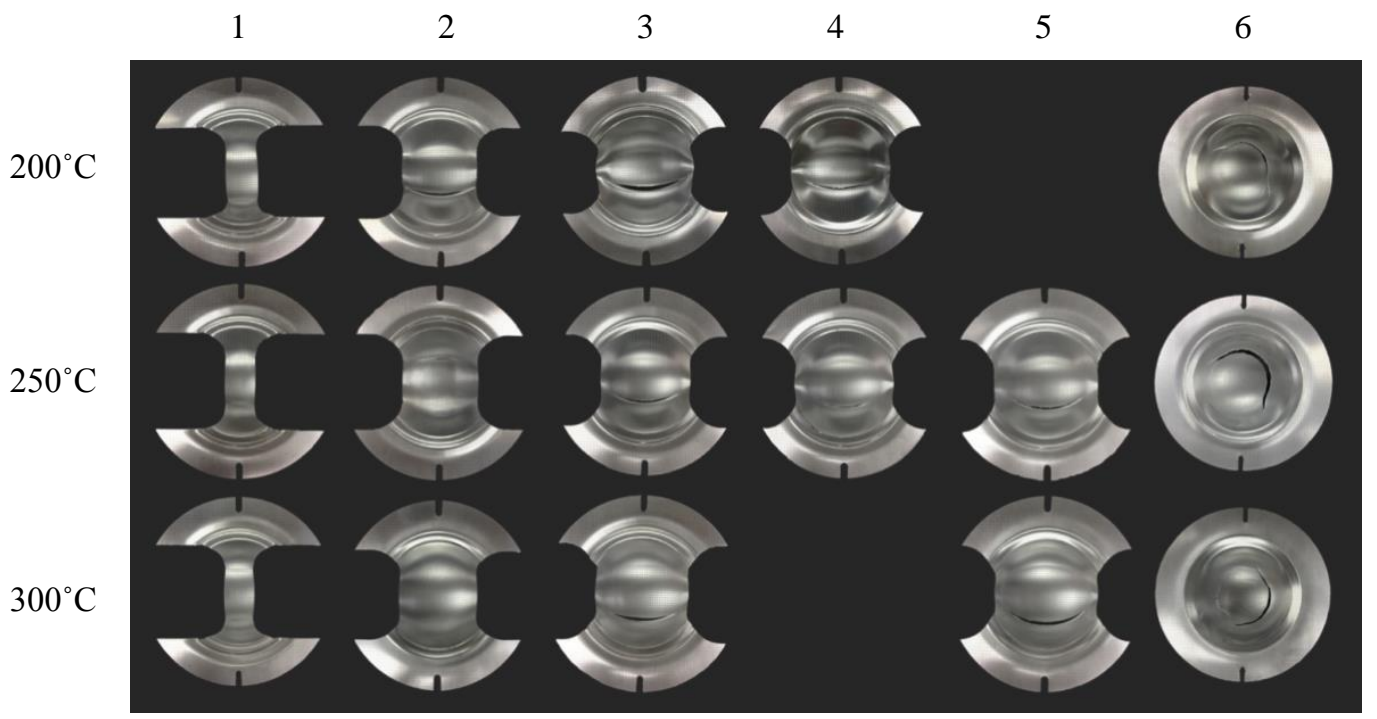

Figure 3.Specimens after forming at a speed of $75 \mathrm{~mm} / \mathrm{s}$ at different temperatures. 
Since an FLC represents the beginning of localized necking but not failure strains of materials, and it is impossible to experimentally measure limit strains just before the onset of necking, ISO 12004-2:2008 standard ${ }^{15}$ recommends a curve fitting method to identify and determine forming limits. The full-field view of strains including major strain and minor strain was obtained by measuring the displacement of dots after forming using the GOM ARGUS photogrammetry system (Figure 4(a)). Virtual cross sections were created for obtaining the strain distribution of formed specimens. Two boundaries of two fit windows were defined by the standard method in true strain-section length plots. On some specimens, physical cracks were observed, and thus the size of deformed grids at the crack were larger, causing very high major strains from GOM ARGUS output, as shown in Figure 4(b). The exported strain profiles from GOM ARGUS were processed by inverse parabola fittings to obtain corresponding limit major strains and minor strains for FLCs (Figure 4(b)).

In order to obtain a good overall formability, the materials are expected to have isotropic mechanical properties ${ }^{20}$. Figure 5 illustrates a comparison of normalized thickness variation (t $\left./ \mathrm{t}_{0}\right)$ in different directions (i.e. rolling direction, perpendicular to rolling direction and perpendicular to the crack) for equi-biaxial strain state at a temperature of $250^{\circ} \mathrm{C}$ and a forming speed of $20 \mathrm{~mm} / \mathrm{s}$, where $\mathrm{t}$ and $\mathrm{t}_{0}$ are the current and initial thickness. Thickness was collected from ARGUS software directly. It is observed that the thickness variation in the plane of the specimen has no significant dependence on three directions. In this paper, the thickness data was obtained from the section perpendicular to the crack or severe necking. 


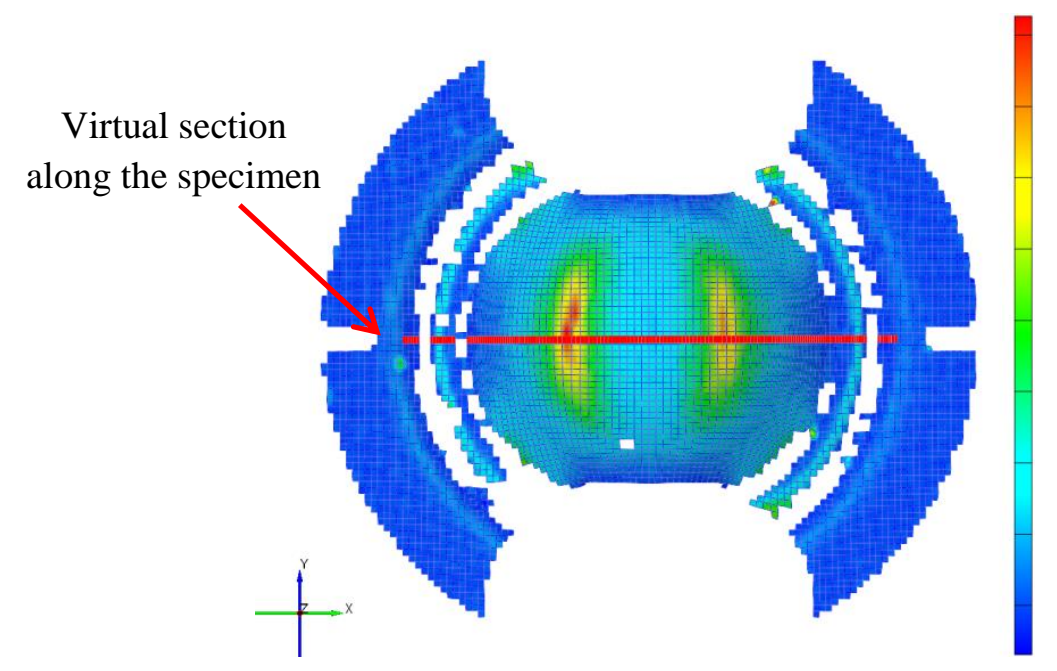

(a) Strain field processed with the GOM ARGUS system

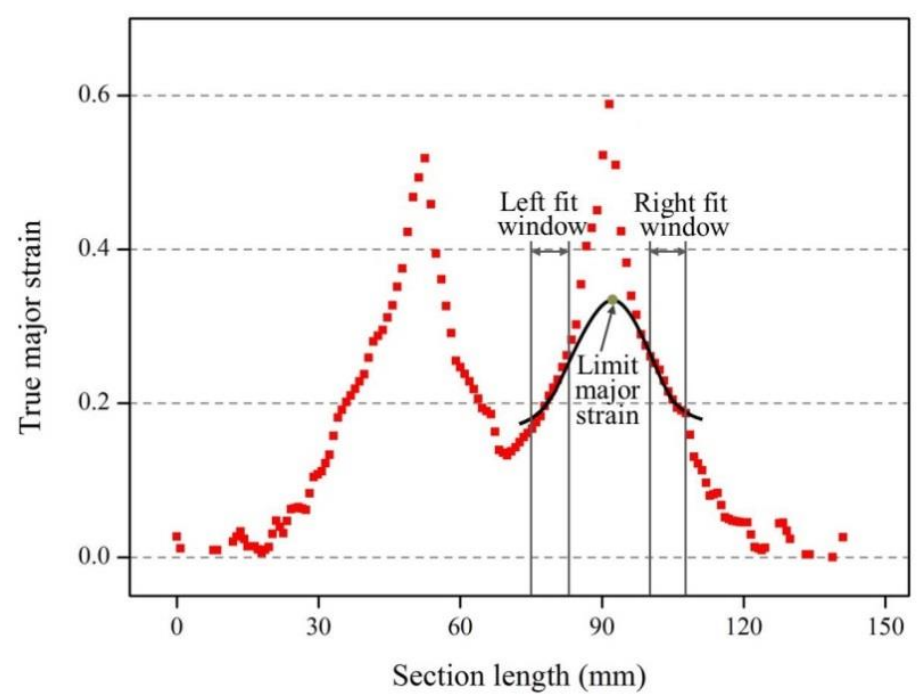

(b) Obtaining the limit major strain by curve fitting

Figure 4. An example showing the collection of data points for an FLC from a tested sample. 


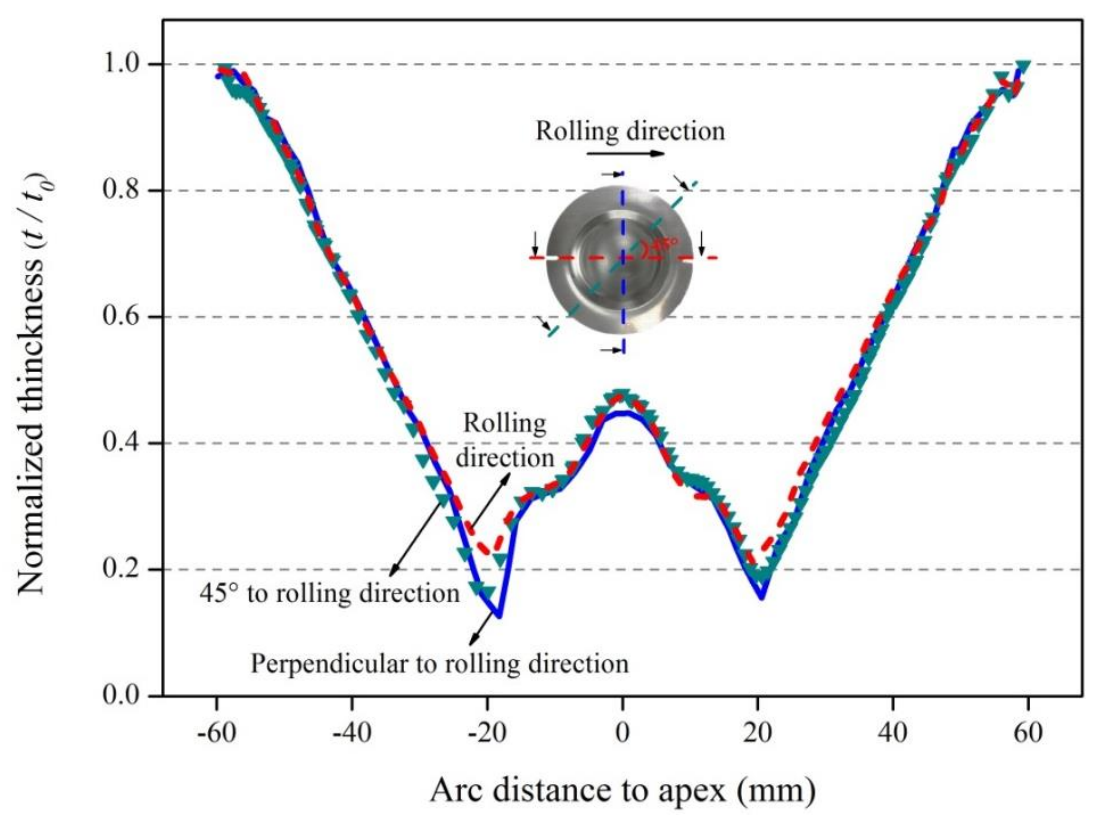

Figure 5. Comparison of normalized thickness variation in different directions for geometry number 6 at $250^{\circ} \mathrm{C}$ with a forming speed of $20 \mathrm{~mm} / \mathrm{s}$.

\section{Computed FLCs}

By processing data for different geometries, strain data for different strain paths were determined and hence the FLCs of AA5754 were obtained through curve fitting (Figure 6). At elevated temperature, the solid-line curves in Figure 6 are interpolated to predict the probable behaviour within the experimental range.

It is found that when the forming speed decreases from $300 \mathrm{~mm} / \mathrm{s}$ to $20 \mathrm{~mm} / \mathrm{s}$, the forming limit increases, and the forming limit in the plane strain state has the largest increase. The FLC is flatter at $20 \mathrm{~mm} / \mathrm{s}$. The forming limit has a relatively larger decrease from $20 \mathrm{~mm} / \mathrm{s}$ to $75 \mathrm{~mm} / \mathrm{s}$ than that from $75 \mathrm{~mm} / \mathrm{s}$ to $300 \mathrm{~mm} / \mathrm{s}$ (Figure 6(a)).In Figure 6(b), it is found that an increase of forming limit from $250^{\circ} \mathrm{C}$ to $300^{\circ} \mathrm{C}$ is about twice of that from $200^{\circ} \mathrm{C}$ to $250^{\circ} \mathrm{C}$ in the plane strain state. These results indicate that high forming limits can be obtained when the warm forming temperatures are in the range of $250^{\circ} \mathrm{C}$ to $300^{\circ} \mathrm{C}$. The V-shape of the FLCs tends to be flatter as temperature increases and forming speed decreases. In summary, lower 
forming speeds and higher temperatures are beneficial for enhancing the forming limit in an isothermal environment.

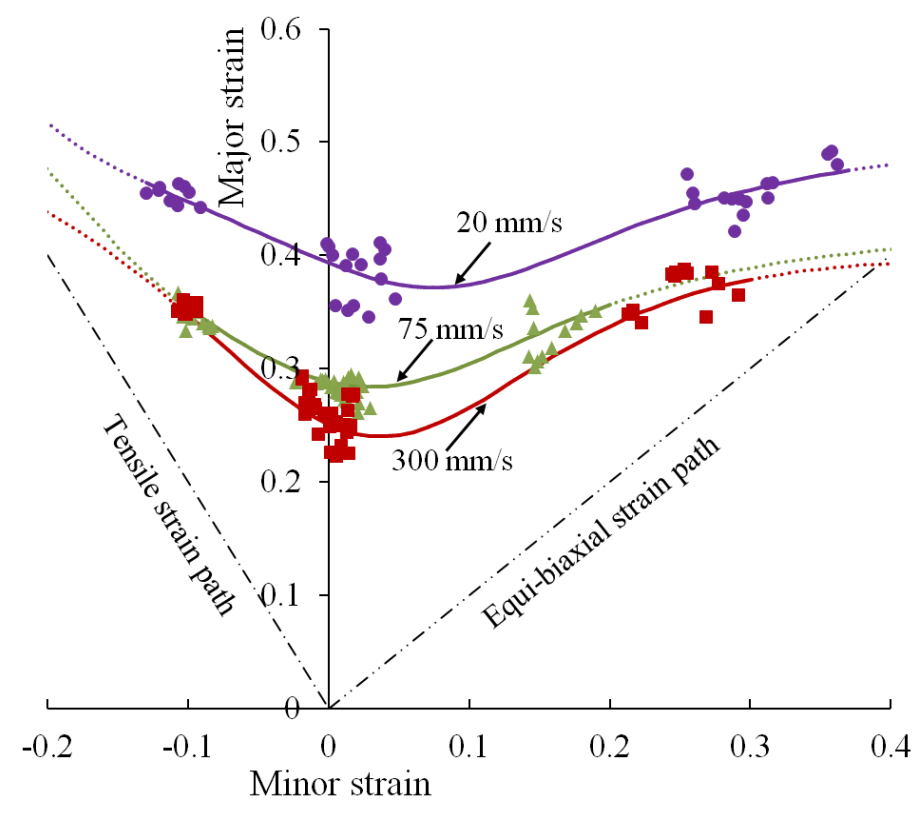

(a) FLCs for different forming speeds at $250^{\circ} \mathrm{C}$

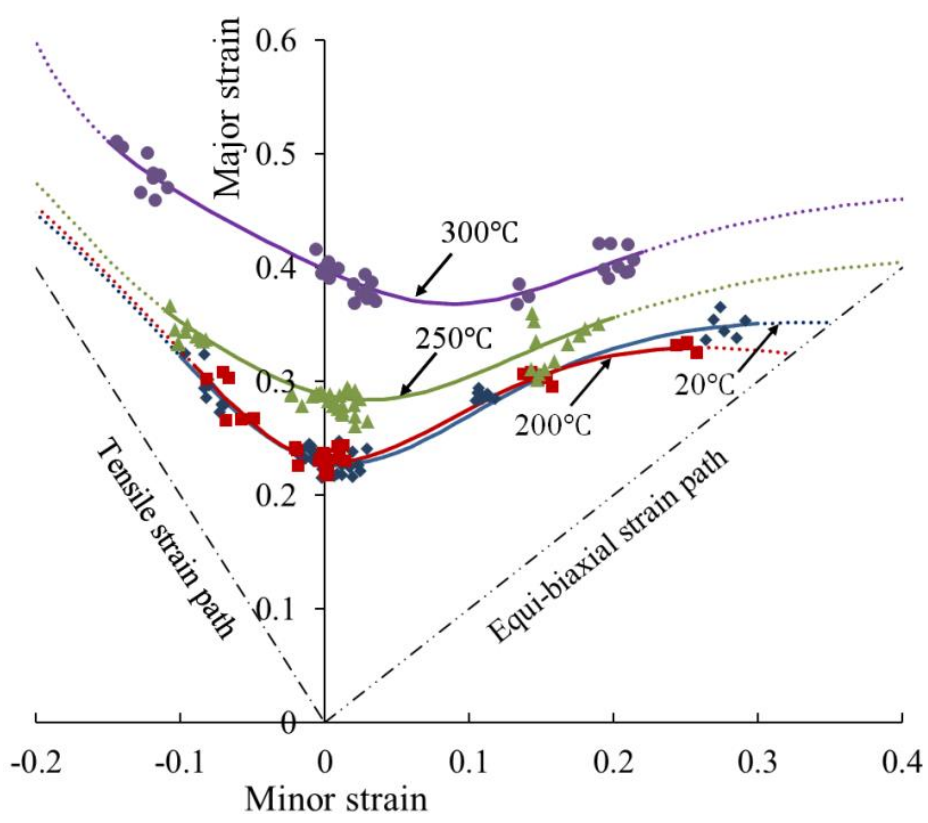

(b) FLCs for different temperatures at $75 \mathrm{~mm} / \mathrm{s}$

Figure 6. FLCs obtained by forming tests at different (a) forming speeds and (b) temperatures. 
Experimental data of thickness variations along the virtual section of specimens has been obtained for different strain paths (Figure 7). It is difficult to accurately measure the distance between two peaks where a localized necking occurs (Figure 4(b)), since the low density of grids associated with a crack results in inaccuracy of the strain in thickness. Therefore, the distance along the virtual section from the location of localized necking to the apex of the dome was measured and the average of the distance between the localized necking and the apex of the dome was calculated and marked in these figures. Thickness variation for the equi-biaxial strain state (Point 6 in Figure 1) is much more dramatic compared to that for Points 1-5 strain paths. In this paper, the data for Point $1-5$ strain paths are studied, and further investigation will be conducted on the data from equi-biaxial specimens. The overall trend of thickness variation can be observed in Figure 7. Qualitatively, with the increase of forming speed or the decrease of temperature, specimens with different geometries tend to have similar trends, i.e. better thickness uniformity and location of fracture closer to the apex of dome.
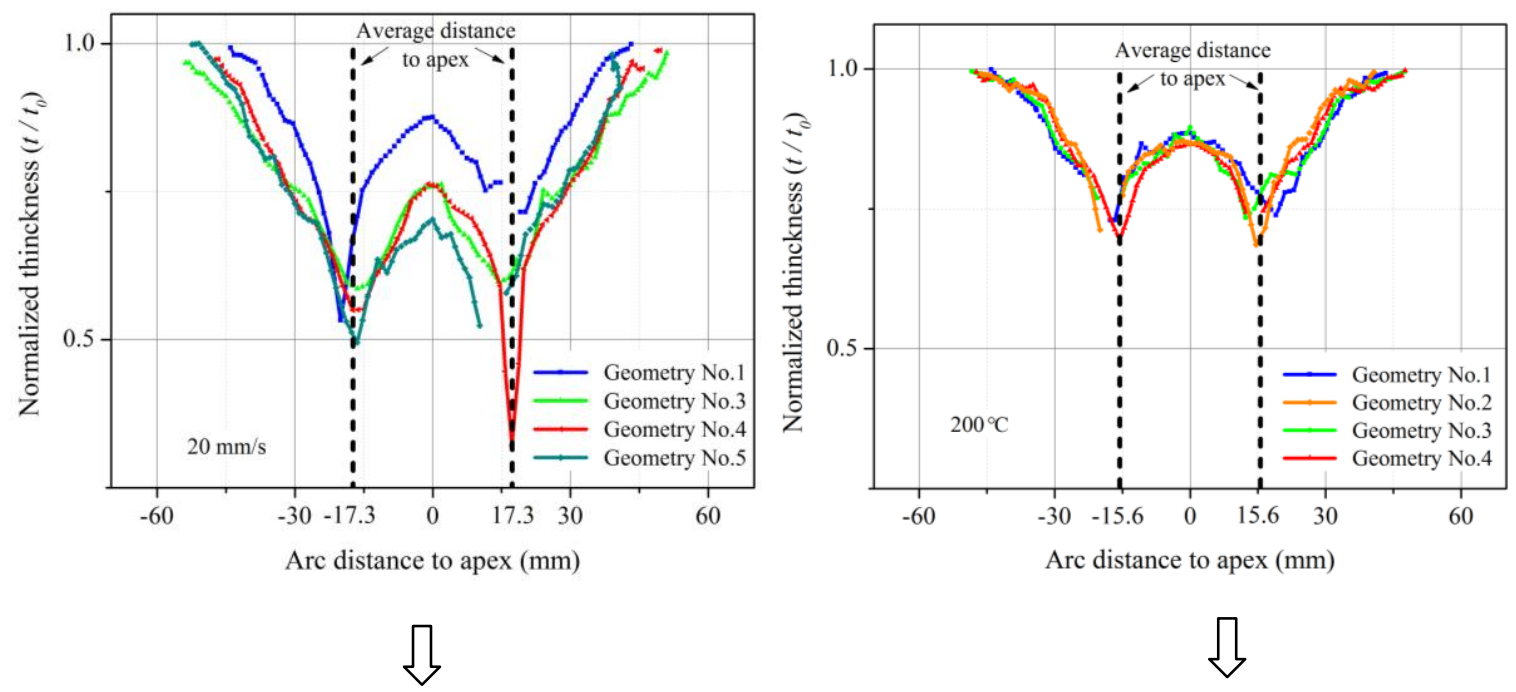

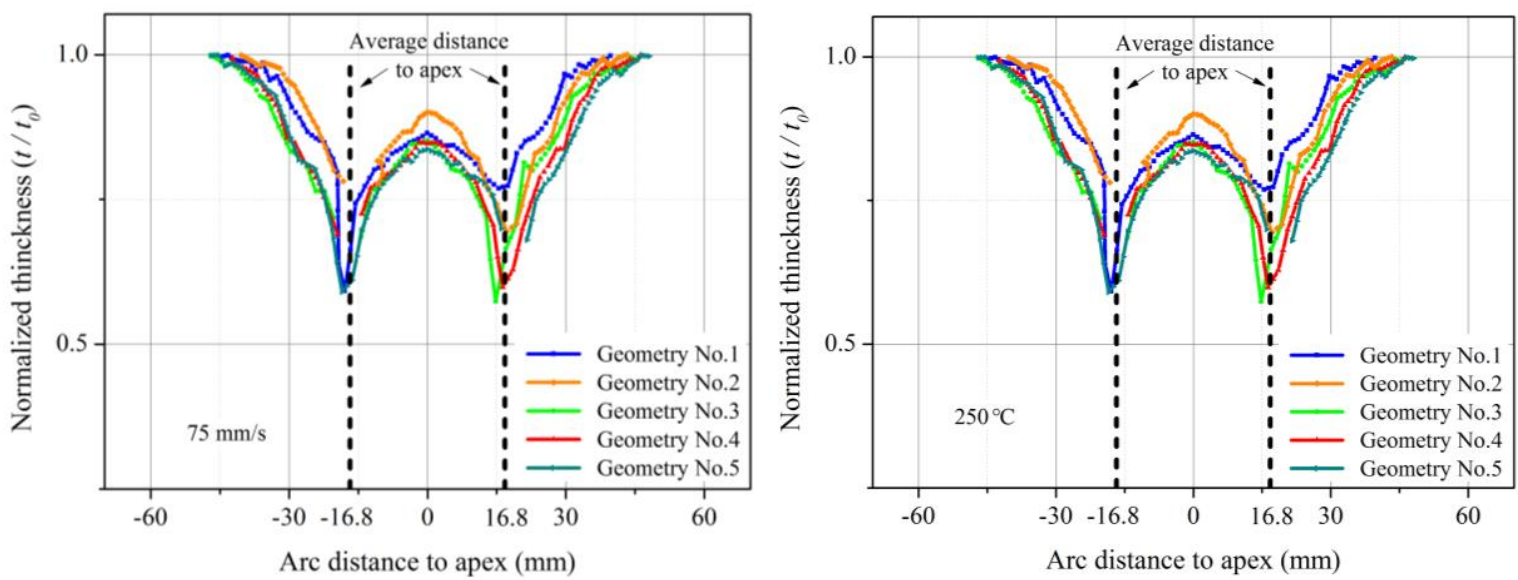

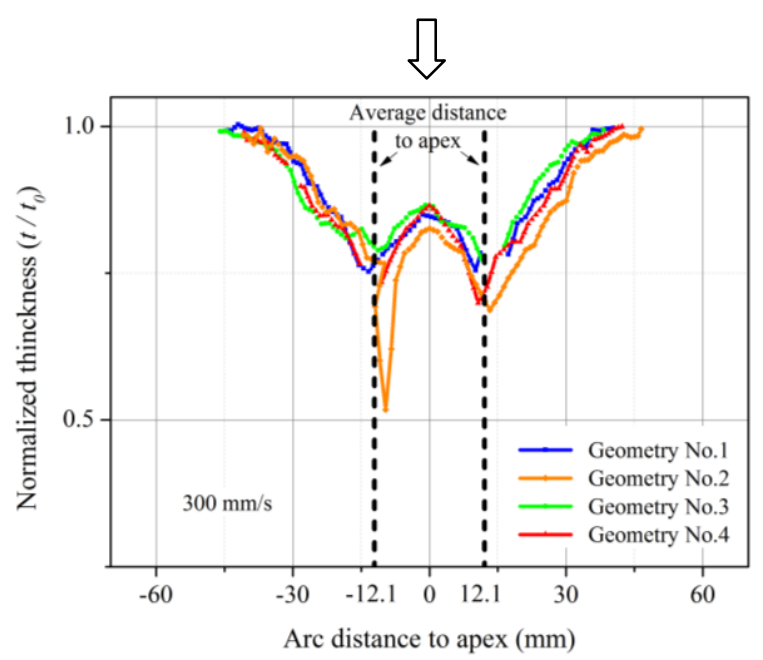

(a) Different forming speeds at $250{ }^{\circ} \mathrm{C}$

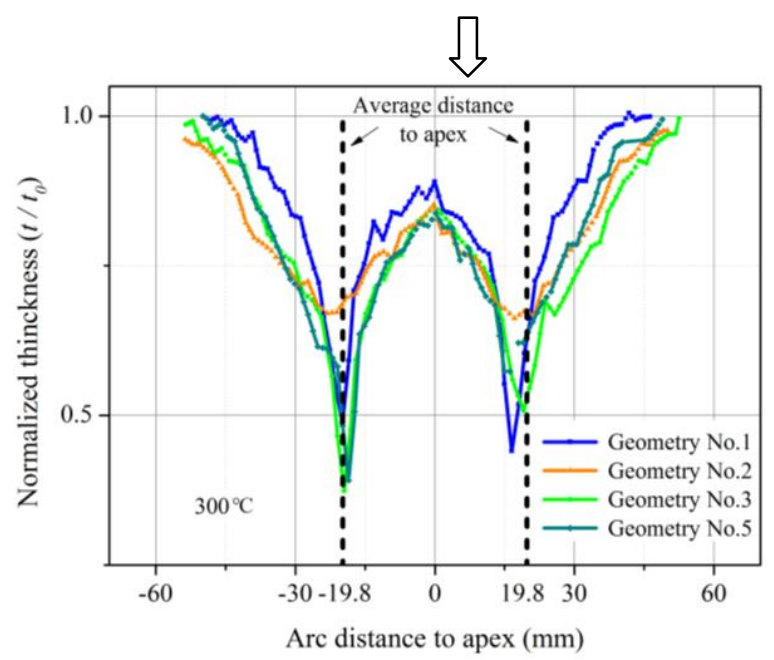

(b) Different temperatures at $75 \mathrm{~mm} / \mathrm{s}$

Figure 7.Thickness variations and arc distances to apex at different (a) forming speeds and at (b) different temperatures.

\section{Discussion}

\section{Effect of forming speed}

The final dome heights of all formed specimens were measured. Since it is difficult to detect an incipient crack and simultaneously stop deformation, a physical crack occurred on the formed specimen in most cases. Values of limit dome heights (LDHs) modified to accord with deformation at failure were calculated by using the geometric relationship among the test set-up, final dome heights and crack widths. Figure8 presents the data of the mean LDH 
at a forming temperature of $250^{\circ} \mathrm{C}$. Most of the specimens formed under a uniaxial strain state broke into two pieces, which causes the final dome height and maximum crack width difficult to be measured. Therefore, the results with a uniaxial strain state are not presented in Figure 8.

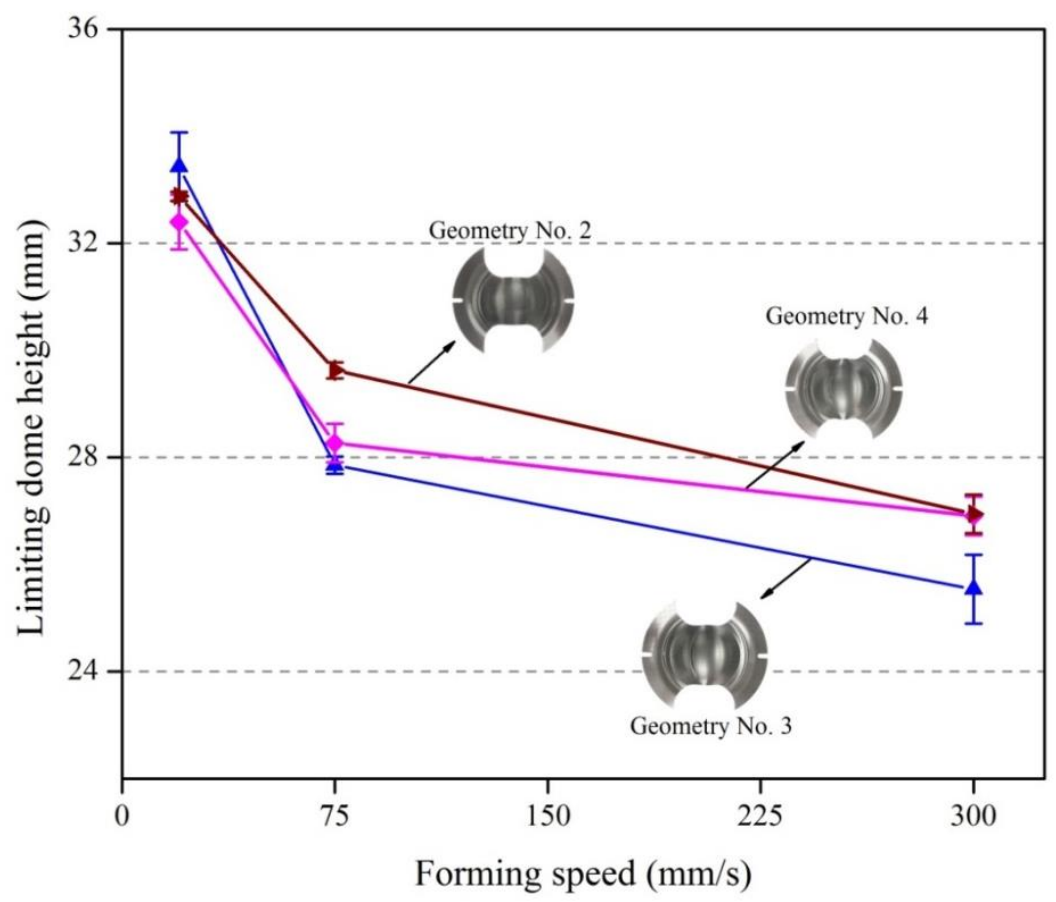

Figure 8. Effect of forming speed on limit dome height at a temperature of $250{ }^{\circ} \mathrm{C}$

As shown in Figure 8, LDH decreases with the increasing forming speed and hence the increasing strain rate, for strain paths $2-4$. Lin $^{18}$ found that for AA5754 at temperatures used in this work, the flow stress increases with increasing strain rate from $0.1 \mathrm{~s}^{-1}$ to $10 \mathrm{~s}^{-1}$. Also they found that strain rate hardening is enhanced when strain rate is increasing, but the elongation to failure decreases with increasing strain rate, which reduces the forming limit of the material. On the other hand, strain hardening increases with increasing strain rate, which can be beneficial to material flow uniformity and stress-transfer, therefore reducing the tendency to localized necking and hence higher dome heights. The combined influence of strain rate hardening and strain hardening may be complex, but higher LDHs can be observed 
at lower forming speeds in Figure 8. This indicates that strain rate hardening is the dominant factor when forming speed varies in the LDH tests.

Figure 9(a) shows normalized thickness $\left(t / t_{0}\right)$ of specimens formed in the plane strain state at different forming speeds, and the locations of $t_{\max }$ and $t_{\min }$. Similarly by comparing the average value of thickness variation $\left(\left(t_{\max }-t_{\min }\right) / t_{\max }\right)$ indifferent strain paths, more uniform thickness is observed at a higher forming speed in Figure 9(b). Significant improvement in thickness uniformity at the highest forming speed is obtained because the strain hardening increases with increasing strain rate, which results in a lower tendency to localized thinning.

As shown in Figure 9(a), forming speed has an effect on the location of the fracture. In ISO standard (ISO 12004-2:2008) for room temperature, the FLC test is considered to be valid when fracture occurs within a distance less than $15 \%$ of the punch diameter away from the apex of the dome. However there is no standard of fracture occurrence distance to validate the test at elevated temperatures. In this study, the fracture occurred within the contact region between the punch and the deformed material is considered to be valid. With a higher forming speed fracture occurs nearer the apex of the dome. As forming speed increases, the high-speed deformation of the material produces better lubrication performance between punch and specimen since fewer scratches were found in the samples with a higher speed. A decreasing friction coefficient enables fracturing to occur on the top of the dome. The arc distance from the location of localised necking (without cracks) to the apex of the dome in Fig. 9(a) was measured, and the results are shown in Fig. 9(c). A similar trend can be found in Figure9(c): the average value of arc distances from the localized necking location to the apex is the smallest at the highest forming speed. 


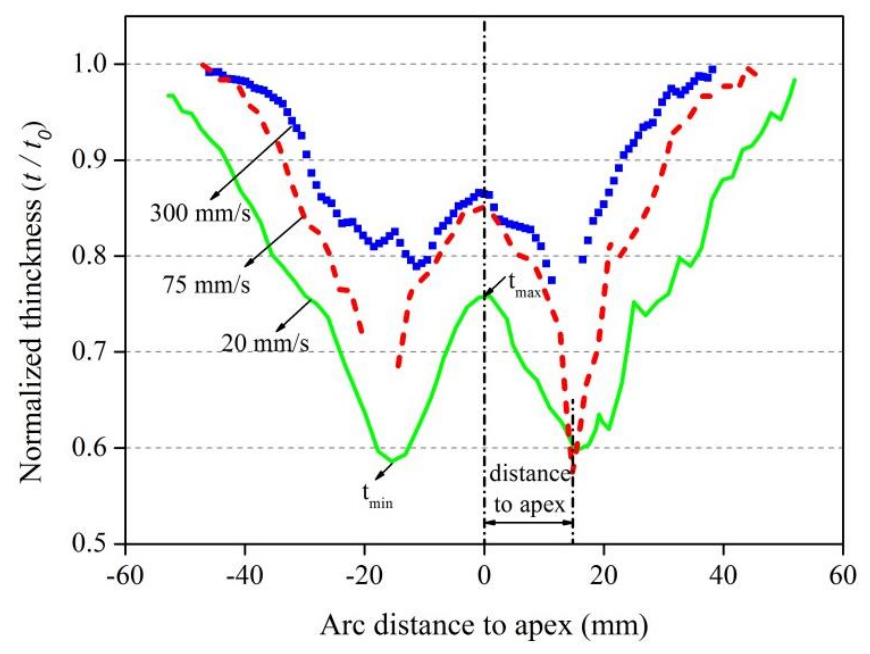

(a) Thickness variation of the specimens formed in the plane strain state

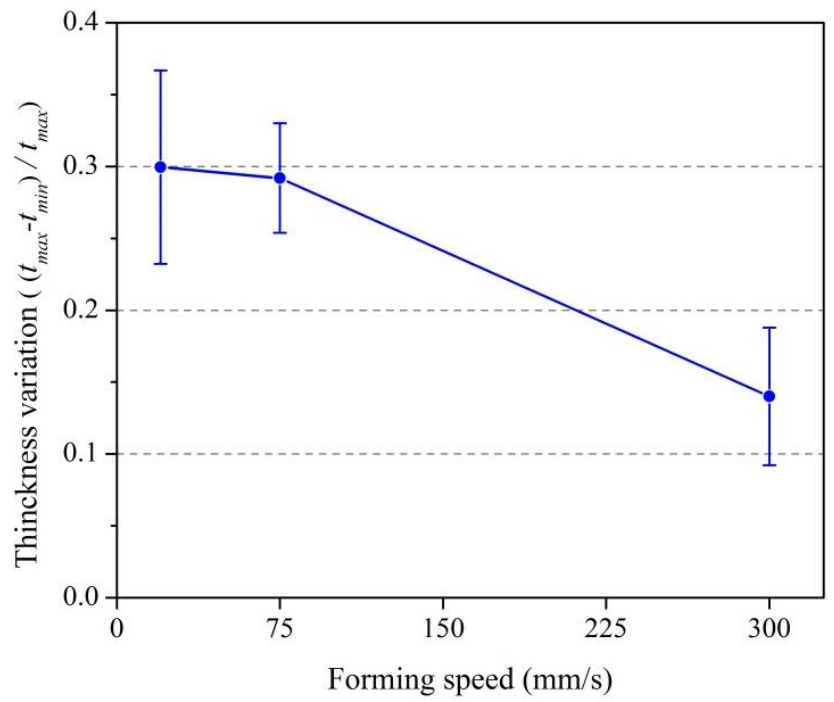

(b) Average values of normalized thickness for strain states of specimens No. 1-5

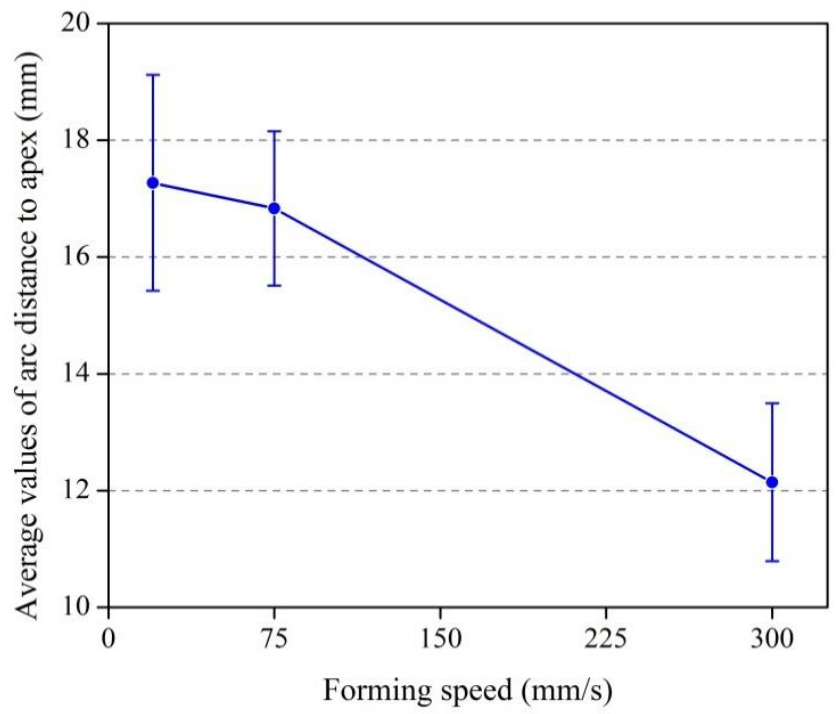

(c)Average values of arc distance from the fracture location to the apex for strain states in specimens No. 1-5

Figure 9. Deformation features at different forming speeds at $250^{\circ} \mathrm{C}$ 


\section{Effect of temperature}

As a consequence of increasing temperature, the LDH generally increases for strain states 2 and 3(Figure 10). When temperature increases from $200^{\circ} \mathrm{C}$ to $300^{\circ} \mathrm{C}$, the flow stress of AA5754 decreases and the strain to failure increases, according to the results of uniaxial tensile tests ${ }^{18}$. The strain hardening at $200^{\circ} \mathrm{C}$ is much higher than that at $300^{\circ} \mathrm{C}$. The yield stress and strain hardening decreases with the increasing temperature. It performs good formability at the highest temperature $300^{\circ} \mathrm{C}$ due to the fact that the elongation is the largest and high ductility can postpone localized deformation, which benefits the formability. However, strain hardening decreases with increasing temperature, and the high strain hardening at a low temperature is beneficial as it results in less tendency to localized necking and thus results in high LDH. Nevertheless, higher LDHs can be observed at higher temperatures in Figure 10, which indicates that the elongation to failure is the sensitive factor when the temperature is varied between LDH tests.

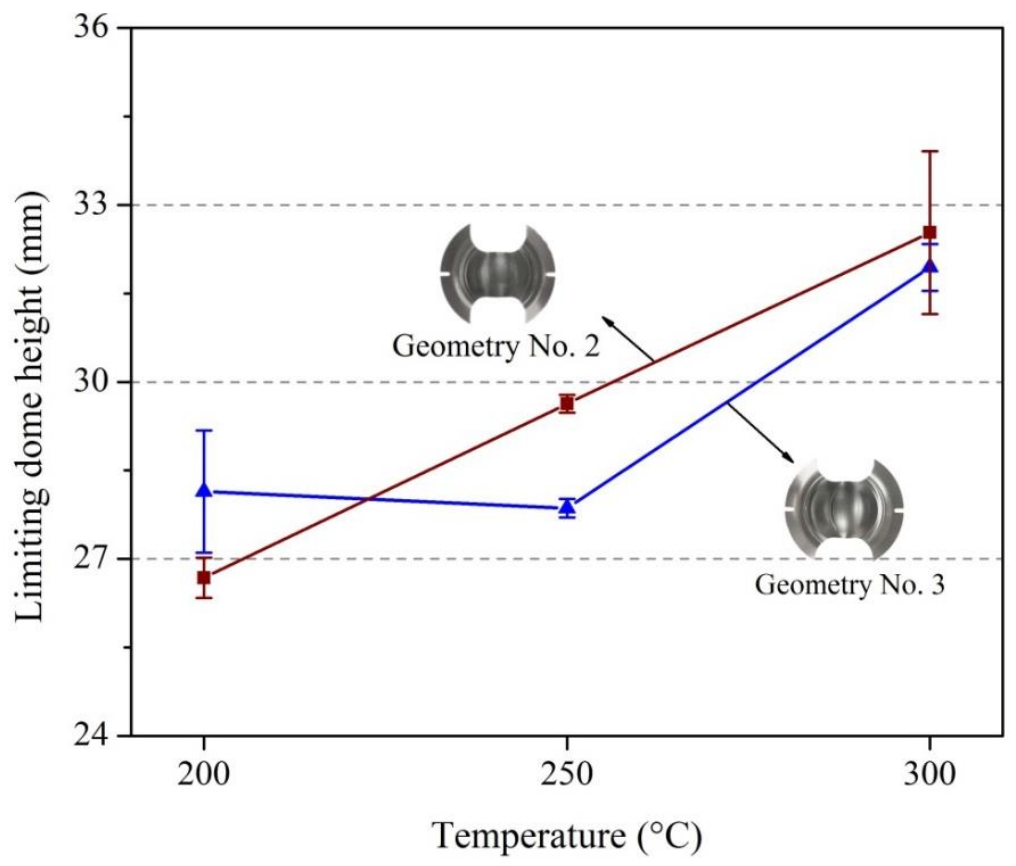

Figure 10. Effect of temperature on limiting dome height at a forming speed of $75 \mathrm{~mm} / \mathrm{s}$ 


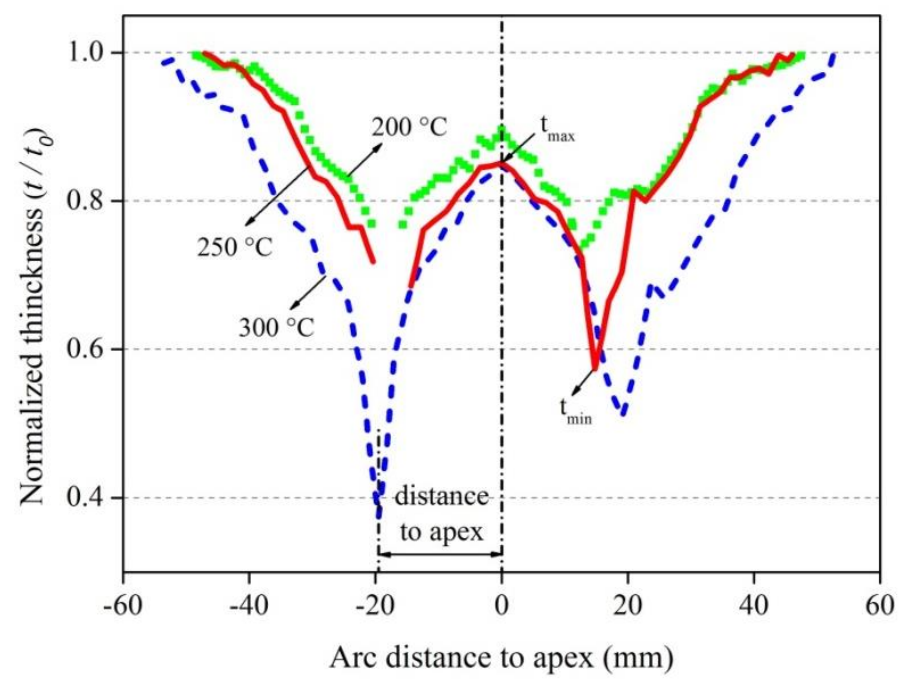

(a)Thickness variation of the specimens in the plane strain state

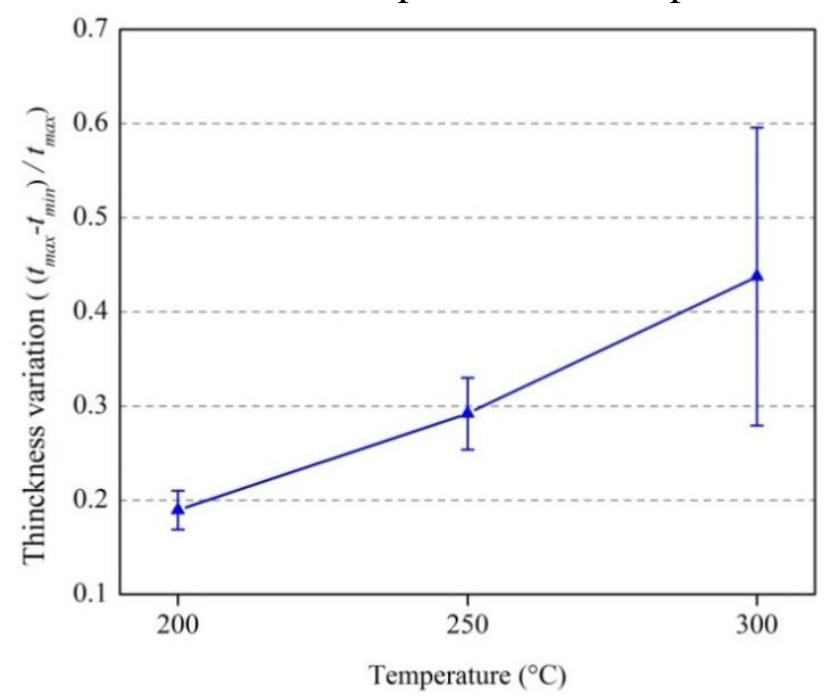

(b)Average values of normalized thickness for strain states in specimens No. 1-5

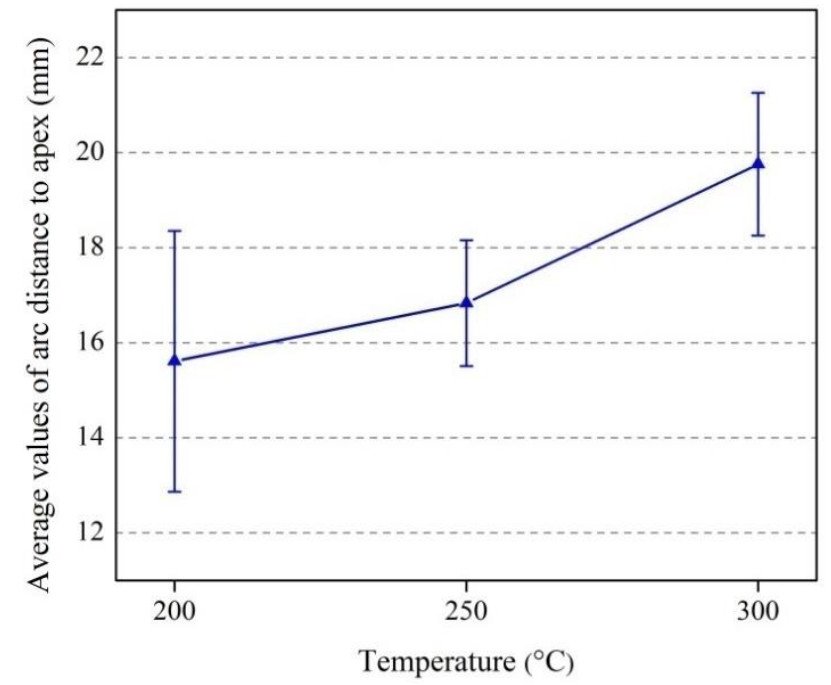

(c) Average values of arc distance from the fracture location to the apex for strain states in specimens No. 1-5

Figure 11. Deformation features at different temperatures at $75 \mathrm{~mm} / \mathrm{s}$ 
Figure 11(a) shows the normalized thickness $\left(t / t_{0}\right)$ of specimens formed in the plane strain state at different temperatures. The distance from the location of fracture to the apex varies with temperature. By comparing the average value of thickness variation $\left(\left(t_{\max }-t_{\min }\right) / t_{\max }\right)$ in different strain paths (Figure 11(b)), a more uniform thickness profile can be seen at a lower temperature. The average thickness variation has a monotonic increase with increasing of forming temperature, which is attributed to the fact that temperature increasing results in an decreasing of strain hardening and thus a higher tendency to localized thinning. It is noticed that there is a relatively large standard deviation at the highest temperature. This means that the forming test presents instability at higher temperatures.

The average value of arc distance from the fracture location to the apex is the highest at the highest temperature of $300^{\circ} \mathrm{C}$ (Figure.11(c)). For a lower temperature, the fracture occurs near the apex of the dome. It is because elevated temperature increases surface oxidation of metal surface and has a negative influence on the properties of the lubricant ${ }^{21}$, which contributes to increasing the friction coefficient. In the LDH tests, fracture occurred in the contact region for all specimens at different temperatures even though the fracture location of is not at the apex of the dome. In order to avoid the effect of friction coefficient on the measured forming limits, the Marciniak test or a planar tensile test system is good approaches to determine the FLD of a material in future.

\section{Conclusions}

This study considers the effects of forming speed and temperature on the formability and deformation features of formed specimens in dome forming limit tests of AA5754. The FLCs of AA5754 are determined at the elevated temperatures and different high forming speeds in a good isothermal environment. 
The forming limit increases significantly with increasing temperature from $200^{\circ} \mathrm{C}$ to $300^{\circ} \mathrm{C}$ and decreasing forming speed from $300 \mathrm{~mm} / \mathrm{s}$ to $20 \mathrm{~mm} / \mathrm{s}$. Thus warm forming processes at high temperature and relatively low forming speed will be beneficial for work-piece formability. However, the thickness of formed specimens is more uniform at higher forming speeds and lower temperatures within the investigated ranges. Furthermore, the thickness variation decreases $53.2 \%$ with increasing forming speed from $20 \mathrm{~mm} / \mathrm{s}$ to $300 \mathrm{~mm} / \mathrm{s}$ and decreases $56.7 \%$ with decreasing temperature from $300^{\circ} \mathrm{C}$ to $200^{\circ} \mathrm{C}$. Because of the friction effects, the arc distance from the fracture location to the apex of the formed specimen decreases $29.7 \%$ with increasing forming speed from 20 to $300 \mathrm{~mm} / \mathrm{s}$ and, on the contrary, increases $26.5 \%$ with increasing temperature from $200^{\circ} \mathrm{C}$ to $300^{\circ} \mathrm{C}$.

It is noted that knowledge of deformation features such as uniformity of formed specimens, the location of fractures, in addition to the forming limits, can be used to understand and optimize warm forming processes for aluminium alloys. Numerical simulation will be used to convert the forming speeds to strain rates at the localised location. A set of constitutive equations based on continuum damage mechanics will be proposed and the material constants in the damage constitutive equation will be calibrated based on the formability test results.

\section{Acknowledgements}

Financial support from the UK Technology Strategy Board (TSB) high value manufacturing programme for the project of Warm Aluminium Forming Technologies (WAFT) is gratefully acknowledged. The authors would like to thank Novelis UK Ltd for the supply of material. 


\section{References}

1. Toros S, Ozturk F and Kacar I. Review of warm forming of aluminum-magnesium alloys. Journal of Materials Processing Technology. 2008; 207: 1-12.

2. Bolt PJ, Lamboo NAPM and Rozier PJCM. Feasibility of warm drawing of aluminium products. Journal of Materials Processing Technology. 2001; 115: 118-21.

3. Zhang SH. Developments in hydroforming. Journal of Materials Processing Technology. 1999; 91: 236-44.

4. Karbasian $\mathrm{H}$ and Tekkaya AE. A review on hot stamping. Journal of Materials Processing Technology. 2010; 210: 2103-18.

5. Olla P and Virdis PF. High Temperature Deformation of a Commercial Aluminum Alloy. Metallurgical and Materials Transactions. 1987; 18: 293-301.

6. $\quad \mathrm{Li} \mathrm{D}$ and Ghosh AK. Biaxial warm forming behavior of aluminum sheet alloys. Journal of Materials Processing Technology. 2004; 145: 281-93.

7. Mohamed MS, Foster AD, Lin J, Balint DS and Dean TA. Investigation of deformation and failure features in hot stamping of AA6082: Experimentation and modelling. International Journal of Machine Tools and Manufacture. 2012; 53: 27-38.

8. Abedrabbo N, Pourboghrat F and Carsley J. Forming of AA5182-O and AA5754-O at elevated temperatures using coupled thermo-mechanical finite element models. International Journal of Plasticity. 2007; 23: 841-75.

9. Pandey A, Khan AS, Kim E-Y, Choi S-H and Gnäupel-Herold T. Experimental and numerical investigations of yield surface, texture, and deformation mechanisms in AA5754 over low to high temperatures and strain rates. International Journal of Plasticity. 2013; 41: 165-88.

10. Hashemi $\mathrm{R}$, Mamusi $\mathrm{H}$ and Masoumi A. A simulation-based approach to the determination of forming limit diagrams. Proceedings of the Institution of Mechanical Engineers, Part B: Journal of Engineering Manufacture. 2014; 228: 1582-91.

11. Gerdooei M and Dariani BM. Strain-rate-dependent forming limit diagrams for sheet metals. Proceedings of the Institution of Mechanical Engineers, Part B: Journal of Engineering Manufacture. 2008; 222: 1651-9.

12. Dariani BM, Liaghat GH and Gerdooei M. Experimental investigation of sheet metal formability under various strain rates. Proceedings of the Institution of Mechanical Engineers, Part B: Journal of Engineering Manufacture. 2009; 223: 703-12.

13. Hsu E, Carsley JE and Verma R. Development of Forming Limit Diagrams of Aluminum and Magnesium Sheet Alloys at Elevated Temperatures. Journal of Materials Engineering and Performance. 2008; 17: 288-96.

14. Manikandan G, Verma RK and Biswas P. Effect of friction in stretch forming and its influence on the forming limit curve. Proceedings of the Institution of Mechanical Engineers, Part B: Journal of Engineering Manufacture. 2015; 229: 973-81.

15. ISO 12004-2:2008 Metallic materials. Sheet and strip. Determination of forming-limit curves. Part 2: Determination of forming-limit curves in the laboratory.

16. Naka T, Torikai G, Hino R and Yoshida F. The effects of temperature and forming speed on the forming limit diagram for type 5083 aluminium-magnesium alloy sheet. Journal of Materials Processing Technology. 2001; 113: 648-53.

17. Palumbo G, Sorgente D and Tricarico L. The design of a formability test in warm conditions for an AZ31 magnesium alloy avoiding friction and strain rate effects. International Journal of Machine Tools and Manufacture. 2008; 48: 1535-45.

18. Lin J, Mohamed M, Balint D and Dean T. The development of continuum damage mechanics-based theories for predicting forming limit diagrams for hot stamping applications. International Journal of Damage Mechanics. 2013; 23: 684-701. 
19. Demeri MY. Drawbeads in Sheet Metal Forming. Journal of Materials Engineering and Performance. 1993; 2: 863-6.

20. Miller WS, Zhuang L, Bottema J, et al. Recent development in aluminium alloys for the automotive industry. Materials Science and Engineering. 2000; 280: 37-49.

21. Lloyd DJ. Recent developments in controlling the architecture for property optimization in Al-based materials. Scripta Materialia. 2013; 68: 13-6. 